\title{
FGFI-gold nanoparticle conjugates targeting FGFR efficiently decrease cell viability upon NIR irradiation
}

This article was published in the following Dove Press journal:

International Journal of Nanomedicine

28 November 2012

Number of times this article has been viewed

\author{
Anna Szlachcic' \\ Katarzyna Pala' \\ Malgorzata Zakrzewska' \\ Piotr Jakimowicz' \\ Antoni Wiedlocha ${ }^{2}$ \\ Jacek Otlewski' \\ 'Department of Protein Engineering, \\ Faculty of Biotechnology, University \\ of Wroclaw, Poland; ${ }^{2}$ Centre for \\ Cancer Biomedicine, Department of \\ Biochemistry, Institute for Cancer \\ Research, The Norwegian Radium \\ Hospital, Oslo University Hospital, \\ Oslo, Norway
}

\begin{abstract}
Fibroblast growth factor receptors (FGFRs) are overexpressed in a wide variety of tumors, such as breast, bladder, and prostate cancer, and therefore they are attractive targets for different types of anticancer therapies. In this study, we designed, constructed, and characterized FGFR-targeted gold nanoconjugates suitable for infrared-induced thermal ablation (localized heating leading to cancer cell death) based on gold nanoparticles (AuNPs). We showed that a recombinant ligand of all FGFRs, human fibroblast growth factor 1 (FGF1), can be used as an agent targeting covalently bound AuNPs to cancer cells overexpressing FGFRs. To assure thermal stability, protease resistance, and prolonged half-life of the targeting protein, we employed highly stable FGF1 variant that retains the biological activities of the wild type FGF1. Novel FGF1 variant, AuNP conjugates are specifically internalized only by the cells expressing FGFRs, and they significantly reduce their viability after irradiation with nearinfrared light (down to $40 \%$ of control cell viability), whereas the proliferation potential of cells lacking FGFRs is not affected. These results demonstrate the feasibility of FGF1-coated AuNPs for targeted cancer therapy.
\end{abstract}

Keywords: FGF1-conjugates, gold nanoparticles, FGFR-targeted cancer therapy, photothermal therapy

\section{Introduction}

Targeted cancer therapies are nowadays extensively developed as very promising strategies for cancer treatment. Specific delivery of the therapeutic agent to the tumor site provides a benefit of higher efficacy of cancer cell elimination, while being less harmful to the healthy tissues. ${ }^{1}$ One of the molecular targets that can be used to distinguish between the cancerous cells and the surrounding normal cells are transmembrane proteins belonging to the family of fibroblast growth factor receptors (FGFRs), which contains four closely related members (FGFR1-4).

Overexpression of FGFRs has been reported in a wide variety of tumors, such as breast, prostate, bladder, and gastric cancer, and has been associated with tumor progression and poor patient prognosis. ${ }^{2}$ Depending on the localization and cancer type, different types of FGFRs are overexpressed. For example, elevated levels of FGFR1, FGFR2, and FGFR4 are found in breast cancers, the amplification of FGFR2 is observed in gastric cancers, the overexpression of FGFR1 and FGFR3 is associated with papillary thyroid carcinoma, and FGFR4 overexpression occurs in prostate cancers. ${ }^{3,4}$ Moreover, a low level of FGFR expression is found on the surface of noncancer cells in the tumor vicinity. Therefore, FGFRs represent a potential therapeutic target, raising their currently significant interest. ${ }^{5}$ Until now, small molecule tyrosine kinase
Correspondence: Jacek Otlewski

Department of Protein Engineering, Faculty of Biotechnology,

University of Wroclaw, Tamka 2,

50- 137 Wroclaw, Poland

$\mathrm{Tel}+487 \mathrm{I} 3752824$

Fax +48 7I 3752608

Email otlewski@protein.pl 
inhibitors and specific antibodies have been developed and tested to target FGFRs in various cancer types. ${ }^{6}$

In this study, we employed a natural ligand of FGFR, fibroblast growth factor 1 (FGF1) as a targeting agent specifically aimed at cancer cells. FGF1 is a member of a large family of growth factors involved in diverse cellular processes such as cell proliferation, migration, angiogenesis, as well as embryonic and fetal development. ${ }^{7}$ FGF1 interacts with all four FGFRs, and upon receptor binding and activation, it is effectively internalized into the cell. This feature makes this growth factor a particularly useful targeting agent.

One of the biophysical features of FGF1 that limits its potential pharmacological use is its poor stability and relatively short half-life in vivo. Its denaturation temperature is close to $40^{\circ} \mathrm{C}$, the physiological temperature at which almost half of the protein molecules exist in an unfolded state. To overcome stability limitations of the wild type (wt) FGF1 we took advantage of highly stable triple mutants previously engineered by us with a denaturation temperature of $61.5^{\circ} \mathrm{C}{ }^{8}$

Targeted therapy can be supported with recent advances in nanobiotechnology. One of the recently revisited and actively developed techniques is infrared-driven thermal ablation of tumor cells. Metal nanoparticles of defined size can absorb near-infrared (NIR) light, leading to a temperature increase to over $40^{\circ} \mathrm{C} .{ }^{9}$ Such an elevated temperature is sufficient for the direct killing of tumor cells or for sensitizing them to chemo- or radiotherapy. ${ }^{10,11}$ Among extensively studied metal nanoparticles, gold nanoparticles (AuNPs) are considered to be well suited for cancer therapy and for diagnostic applications due to their structural, optical, and chemical properties such as their stability in physiological conditions, infrared radiation response, and low immunogenicity in vivo. ${ }^{12}$ In order to achieve tumor-specific and localized thermal effects, nanoparticles can be coated with various targeting molecules that increase their selective cellular binding and internalization through receptor-mediated endocytosis. ${ }^{13}$

Here, we present an AuNP-based system employing a modified FGF1 stable variant as a targeting agent to reach and destroy tumor cells. Our study clearly shows that the engineered growth factor retains its biological activity and stability profile, and upon conjugation with AuNPs is effectively internalized by cells expressing FGFR1 but not by FGFR-deficient cells. Moreover, irradiation with NIR light resulted in significantly decreased viability of FGFRexpressing cells treated with FGF1-conjugated nanoparticles, as compared to treatment with uncoated AuNPs.

\section{Materials and methods \\ Construction, expression, and purification of FGFI variant}

The truncated form of human FGF1 (residues 21-154) cloned in the pET-3c vector was used. Point mutations Gln40Pro, Ser47Ile, His93Gly, Cys117Ser, and N-terminal Cys-GlyGly-Gly insertion were introduced with QuikChange ${ }^{\mathrm{TM}}$ sitedirected mutagenesis kit (Stratagene Cloning Systems, La Jolla, CA) using mutagenic primers (Genomed SA, Warsaw, Poland). Hereafter, the FGF1 variant used in this study will be abbreviated as FGF1 $1_{\mathrm{V}}$ Recombinant FGF1 $1_{\mathrm{V}} \mathrm{FGF} 1 \mathrm{v}$ was expressed at $37^{\circ} \mathrm{C}$ in Escherichia coli BL21(DE3)pLysS strain and purified on a heparin-Sepharose CL-6B. Purity and identity of a resulting protein was confirmed by sodium dodecyl sulfate polyacrylamide gel electrophoresis (SDSPAGE) and mass spectrometry (MS).

\section{Conformational and stability measurements}

In order to evaluate the impact of the introduced mutations on the FGF1 structure, circular dichroism (CD) and fluorescence spectra were collected at a protein concentration of $5 \times 10^{-6} \mathrm{M}$ in $25 \mathrm{mM}$ sodium phosphate buffer, $\mathrm{pH} 7.3$, using a JASCO J-715 spectropolarimeter (JASCO, Inc, Easton, MD) and JASCO FP-750 spectrofluorimeter (JASCO, $\mathrm{Inc})$, respectively. $\mathrm{CD}$ measurements were performed in the 210-260 nm range and fluorescence spectra were recorded in the 300-400 nm range upon excitation at $280 \mathrm{~nm}$.

To determine the stability of $\mathrm{FGF}_{\downarrow}$ a thermal denaturation curve was acquired based on the changes in the fluorescence emission intensity at $353 \mathrm{~nm}$ of the tryptophan residue (Trp107) excited at $280 \mathrm{~nm}$. Measurements were performed in the presence of $0.7 \mathrm{M} \mathrm{GdmCl}$ in $25 \mathrm{mM}$ sodium phosphate buffer, $\mathrm{pH} 7.3$, and at a protein concentration of $2 \times 10^{-6} \mathrm{M}$. Thermodynamic data were analyzed using PeakFit software (Systat Software, Inc, San Jose, CA), assuming a two-state reversible equilibrium transition.

\section{Gold colloid synthesis}

Among several procedures of AuNPs synthesis, ${ }^{14,15}$ the protocol based on the reduction of chloroauric acid by sodium citrate and tannic acid was applied. ${ }^{16,17}$ Briefly, a $20 \mathrm{~mL}$ solution containing $4 \mathrm{~mL} \mathrm{1 \%} \mathrm{(w/v)} \mathrm{trisodium} \mathrm{citrate}$

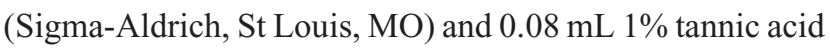
(Sigma-Aldrich) was simultaneously added to the solution $(80 \mathrm{~mL})$, which contained $1 \mathrm{~mL} \mathrm{1 \% (w/v)} \mathrm{chloroauric}$ acid (Sigma-Aldrich). The mixture was heated to $60^{\circ} \mathrm{C}$ for 
20 minutes, with magnetic stirring until it became purple. Then it was cooled down to room temperature. The dispersion of nanoparticles (colloid) was verified by measurement of ultraviolet-visible spectroscopy (UV-Vis) spectrum using a Cary 300 spectrophotometer (Varian Medical Systems, Palo Alto, CA). The size was determined by the dynamic light scattering (DLS) Zetasizer version 6.00 beta 2 (Malvern Instruments Ltd, Worcestershire, UK).

\section{Preparation of $\mathrm{FGFI}_{\mathrm{V}}{ }_{-}-\mathrm{AuNP}$ conjugates}

The FGF1 $1_{\mathrm{V}}$-coated AuNPs were prepared by ligand exchange between reduced protein with exposed N-terminal cysteine residue and citrate ions under the protection of nonionic surfactant, n-decyl- $\beta$-D-maltoside. Freshly synthesized AuNP colloids in the aqueous phase were stabilized with citrate counter ions. The addition of nonionic detergent replaced the citrate counter ion, producing the stable protected nanoparticles. Fourteen different detergents of four types were tested to choose the optimal one for this procedure. The detergents were added to the $\sim 10 \mathrm{nM}$ solution of gold colloid to reach a final concentration of a two times critical micelle concentration, gently mixed and left for 1 hour at room temperature. $\mathrm{FGF}_{\mathrm{V}}$ was reduced prior to conjugation with $0.5 \mathrm{mM}$ TCEP for 30 minutes at room temperature, and the excess of the reducing agent was removed using desalting column (Zeba, Pierce, Thermo Fischer Scientific, Rockford, IL). The reduced protein was added dropwise to the gold colloid solution, mixed gently and incubated under mild shaking overnight at $4^{\circ} \mathrm{C}$.

Protein was added to a final concentration of $150 \mu \mathrm{M}$ to provide a 15 -fold molar excess over AuNPs. To remove, the unbound $\mathrm{FGF} 1_{\mathrm{V}}$ colloids were centrifuged five times at $10,000 \mathrm{~g}$ for 30 minutes at $4^{\circ} \mathrm{C}$. Supernatants were discarded and nanoparticles were resuspended in sterile phosphate buffer (Life Technologies, Carlsbad, CA). The dispersion of FGF $1_{\mathrm{V}}$-AuNPs was verified by measurement of UV-Vis spectrum using Cary 300 (Varian Medical Systems, Inc) spectrophotometer. The size was determined by the DLS Zetasizer Ver 6.00 beta 2 (Malvern Instruments). The FGF $1_{\text {v }}$-gold conjugates solution was stored at $4{ }^{\circ} \mathrm{C}$. The concentration of FGF $1_{V}$ conjugated to the AuNPs was estimated using modified Bradford assay (Bio-Rad Protein Assay, Bio-Rad Laboratories, Hercules, CA), with the FGF1_-based calibration.

\section{Mass spectrometry}

The presence of the $F G F 1_{V}$ bound to the surface of nanoparticles was confirmed by matrix-assisted laser desorption/ionization time-of-flight MS on Applied Biosystems 4800 (Life Technologies). Colloid-bound FGF1 was either reduced with $0.5 \mathrm{M}$ dithiothreitol (DTT) or to 0.1 M tris(2-carboxyethyl)phosphine (TCEP) for 1 hour at $37^{\circ} \mathrm{C}$, or trypsin digested with subsequent identification of tryptic peptides. The supernatant from the last wash of the conjugates' preparation was also subjected to MS analysis in order to confirm the absence of unbound $F G F 1_{V}$ in the colloid solution.

\section{Cell culture}

BJ cells were grown in Quantum 333 medium (PAA Laboratories $\mathrm{GmbH}$, Pasching, Austria) and mouse fibroblast (NIH 3T3) cells were cultured in Quantum 333 medium containing $2 \%$ bovine serum (Life Technologies). U2OS or U2OS stably transfected with FGFR1 (U2OS R1) cells were grown in Dulbecco's modified Eagle's medium (Life Technologies) containing $10 \%$ fetal calf serum (PAA Laboratories $\mathrm{GmbH}$ ). Cells were seeded into tissue culture plates the day preceding the start of the experiment. U2OS R1 cells were a kind gift from Dr Ellen M Haugsten from The Norwegian Radium Hospital.

\section{Proliferation assays}

The serum-starved NIH 3 T3 cells grown on the 96-well plates were treated with FGF1 wt, FGF $1_{v}, F G F 1_{v}$-AuNP conjugates, and AuNPs in the presence of heparin $(10 \mathrm{U} / \mathrm{mL})$. After incubation for 48 hours, $5 \mathrm{mg} / \mathrm{mL}$ MTT solution (3-(4,5-dimethylthiazol-2-yl)-2,5-diphenyltetrazolium bromide) was added to each well and the cells were incubated for 4 additional hours. Then equal volume of lysing buffer (13.5\% sodium dodecyl sulphate (SDS), 45\% dimethylformamide (DMF)) was added, and after 24 hours the absorbance of dissolved formazan crystals (570 nm) was read on a Spectra Max 340 enzyme-linked immunosorbent assay plate reader (Molecular Devices LLC, Sunnyvale, CA). Alternatively, AlamarBlue (Life Technologies) was added to cells treated with FGF $1_{v}$, FGF $1_{v}$-AuNPs, or AuNPs, and after 4 hours the fluorescence of the reduced form of the dye was measured on a Spectra Max Gemini XS fluorescence plate reader (Molecular Devices LLC). FGF1 wt and FGF $1_{v}$ were added to the cells at concentrations of 1,10 , and $100 \mathrm{ng} / \mathrm{mL}$. For all cellular experiments, we used the same system of concentration notation; $1 *, 10^{*}$, and $100^{*} \mathrm{ng} / \mathrm{mL} \mathrm{FGF} 1_{\mathrm{v}}$-AuNPs denotes the concentration of $\mathrm{FGF}_{\mathrm{v}}$ bound to AuNPs, while $1 * *$, $10 * *$, and $100 * * \mathrm{ng} / \mathrm{mL}$ AuNPs denotes the concentration of AuNPs equal to the concentration of AuNPs in $1^{*}, 10^{*}$, and $100 * \mathrm{ng} / \mathrm{mL} \mathrm{FGF} 1_{\mathrm{v}}$-AuNPs. 


\section{Activation of signaling cascades}

Serum-starved NIH 3T3 were stimulated for 15 minutes with FGF $1_{\triangleright} F G F 1_{v}$-AuNPs, or AuNPs in the presence of heparin (10 units $/ \mathrm{mL}$ ). Cells were then washed with phosphate buffered saline, lysed with SDS sample buffer, and sonicated. Total cell lysates were subjected to SDS-PAGE separation and Western blot analysis. Membranes were probed with antiphospho-p44/42 MAP kinase antibody (Thr202/ Tyr204) (p-Erk1/2) and anti-p44/42 MAP kinase antibody (Erk1/2) (Cell Signaling Technology, Inc, Danvers, MA), antiphospho-FGFR (Tyr653/Tyr654) (p-FGFR) (Santa Cruz Biotechnology, Inc, Santa Cruz, CA; Cell Signaling Technology, Inc), antiphospho-Akt antibody (Ser473) (p-Akt) (Cell Signaling Technology, Inc), antiphospho-PLC $\gamma$ antibody (Tyr783) (p-PLC $\gamma$ ) (Santa Cruz Biotechnology, Inc), and visualized with horseradish peroxidase-conjugated secondary antibodies (Jackson ImmunoResearch Laboratories, Inc, West Grove, PA) and chemiluminescent substrate (Pierce, Thermo Fisher Scientific).

\section{Confocal microscopy}

Primary amines on the surface of the $\mathrm{FGF} 1_{\mathrm{v}}$ were fluorescently labeled with fluorescein isothiocyanate (FITC) dye (Sigma-Aldrich) prior to conjugation with nanoparticles. The excess of free dye was removed with a disposable spin column. FGF $1_{\mathrm{V}}$-FITC was then conjugated to AuNPs using a detergent exchange approach described above.

Serum-starved U2OS and U2OS R1 cells cultured on glass coverslips were incubated with $100 \mathrm{ng} / \mathrm{mL}$ labeled FGF $1_{\mathrm{V}}$ and a respective amount of $F G F 1_{\mathrm{v}}$-gold conjugates in the presence of heparin $(10 \mathrm{U} / \mathrm{mL})$ for 30 minutes at $37^{\circ} \mathrm{C}$, which were then washed twice with phosphate buffered saline followed by fixation with a formalin solution (Sigma-Aldrich). The incubation time of the growth factor or $\mathrm{FGF} 1_{\mathrm{V}}$-AuNPs with the cells was chosen based on previously published data on FGF1 internalization at $37^{\circ} \mathrm{C} .{ }^{18,19}$ Finally, the fixed cells were incubated with Hoechst dye to visualize the nuclei. The coverslips were mounted with Mowiol $^{\circledR}$ (SigmaAldrich) and examined with a Zeiss LSM510 Meta confocal microscope (Carl Zeiss, Jena, Germany) at the $488 \mathrm{~nm}$ excitation to visualize FITC-labeled FGF $1_{\vee}$ and in the reflectance mode under $633 \mathrm{~nm}$ excitation to visualize AuNPs.

\section{NIR induced hyperthermia}

U2OS, U2OS R1, and BJ cells cultured on 96-well plates were treated with FGF $1_{v}$, uncoated gold colloids, and $\mathrm{FGF} 1_{\mathrm{v}}-\mathrm{AuNPs}$ in the presence of heparin $(10 \mathrm{U} / \mathrm{mL})$ for 1 hour at $37^{\circ} \mathrm{C}$. Then the cells were washed with medium to remove any unbound nanoparticles and they were exposed to NIR light generated by $808 \mathrm{~nm}$ diode laser (1.2 A, OPTEL Opole, Poland) for 20 minutes. A spot of approximately $4 \mathrm{~mm}$ in diameter was exposed to the irradiation with an $808 \mathrm{~nm}$ diode laser in each treated well. The laser was put in the same distance from the bottom of the well, and therefore it was illuminating the same area in each well with the same relative energy in all photothermal experiments. Cell viability has been assessed 12 hours after treatment with the use of MTT assay. Each experiment was repeated four times.

\section{Results \\ Design, expression, and characterization of FGFI mutant}

We converted a poorly stable FGF1 and turned it into a molecule of high stability, increased resistance to degradation, and suitable for precise and site specific conjugation to AuNPs. We took advantage of the FGF $1_{\mathrm{V}}$ that we formerly designed and characterized, containing three mutations (Gln40Pro, Ser47Ile, His93Gly), which provide a dramatic increase of $21^{\circ} \mathrm{C}$ in the denaturation temperature and protect the growth factor against proteolysis. ${ }^{8} \mathrm{Next}$, to ensure precise cysteine-mediated linkage to AuNP, a flexible Cys-GlyGly-Gly linker was introduced at the protein $\mathrm{N}$ terminus. In addition, the exposed Cys117 in the FGF1 molecule was substituted with serine, so that the engineered N-terminal cysteine contained the single thiol group available for the conjugation with a nanoparticle surface (Figure 1A). Ortega et $\mathrm{al}^{20}$ showed that Cys117Ser mutation did not affect protein stability and significantly increased the protein halflife in plasma, which is an additional benefit for therapeutic or diagnostic applications.

$F G F 1_{\mathrm{v}}$ was expressed in E. coli and purified by affinity chromatography using heparin-Sepharose resin. Its CD and fluorescence spectra were virtually identical to the wt protein, indicating that the engineered $F G F 1_{V}$ was native and properly folded (Figure 1B). Thermal denaturation was monitored by the measurement of the single tryptophan residue fluorescence at $353 \mathrm{~nm}$, which was completely quenched in the folded state and significantly recovered upon protein denaturation. We assumed a two-state reversible thermal transition, as we have previously shown, for a large set of FGF1 mutants. ${ }^{8,21}$ Based on the denaturation curve, thermodynamic parameters were calculated using the Santoro-Bolen equation (Figure 1C). ${ }^{22}$ The $\mathrm{T}_{\text {den }}$ value of $\mathrm{FGF} 1_{\mathrm{v}}$ is $60.9^{\circ} \mathrm{C}$, which is $21.5^{\circ} \mathrm{C}$ higher than that of wt FGF1, and closely approximates the $\mathrm{T}_{\text {den }}$ of the previously 
A
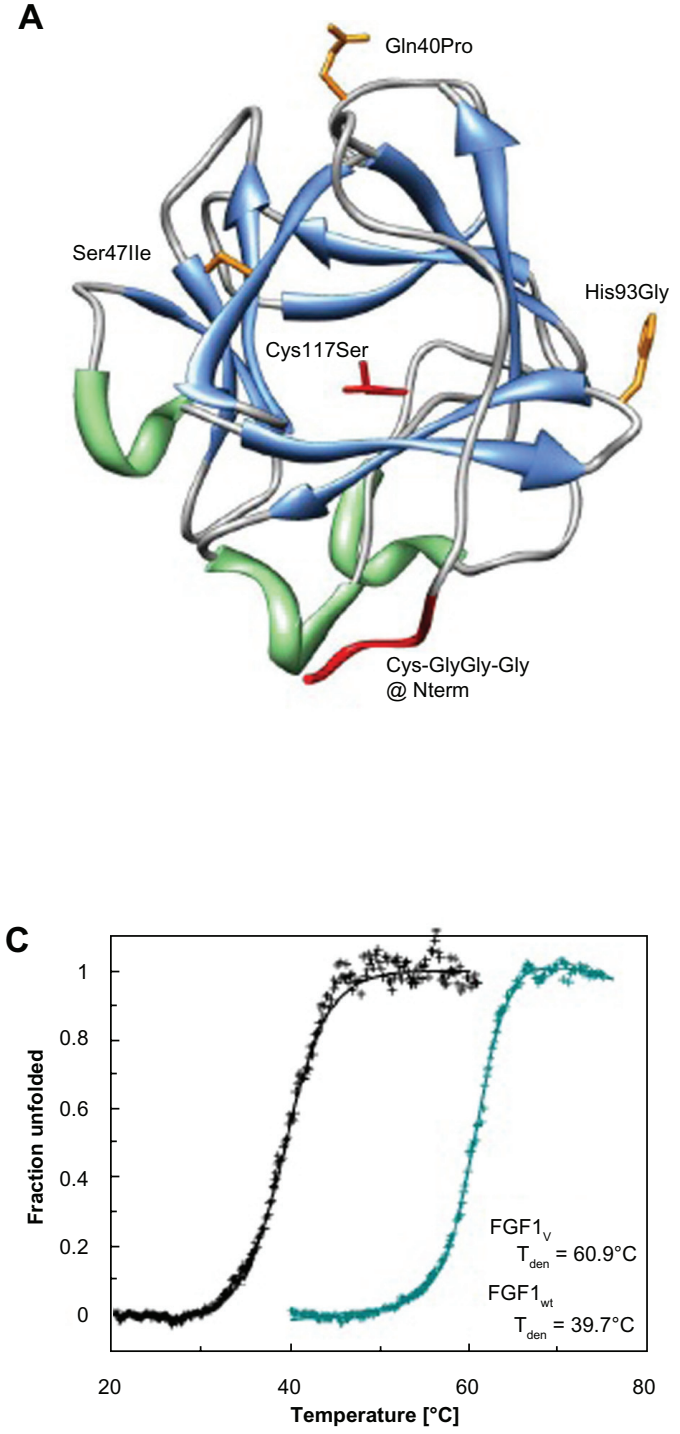

B
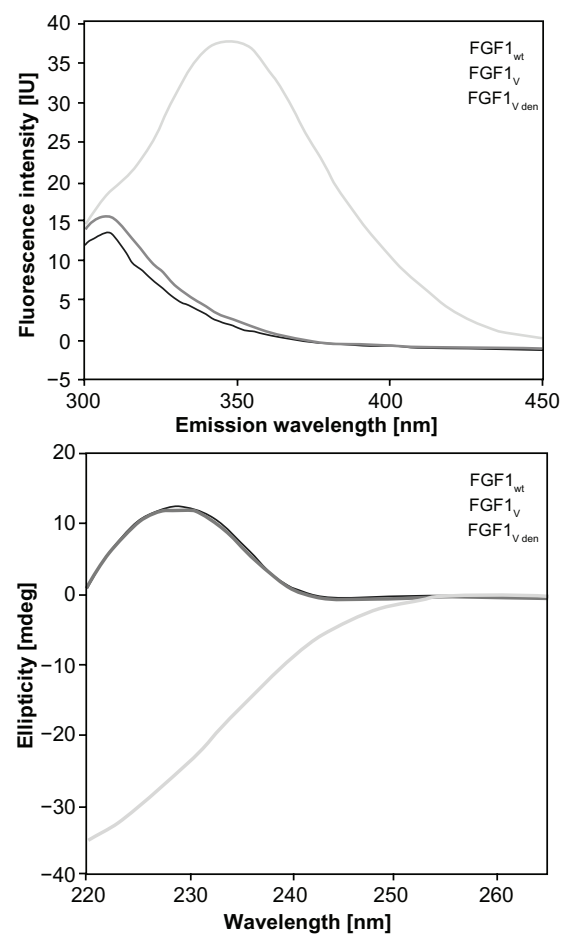

D

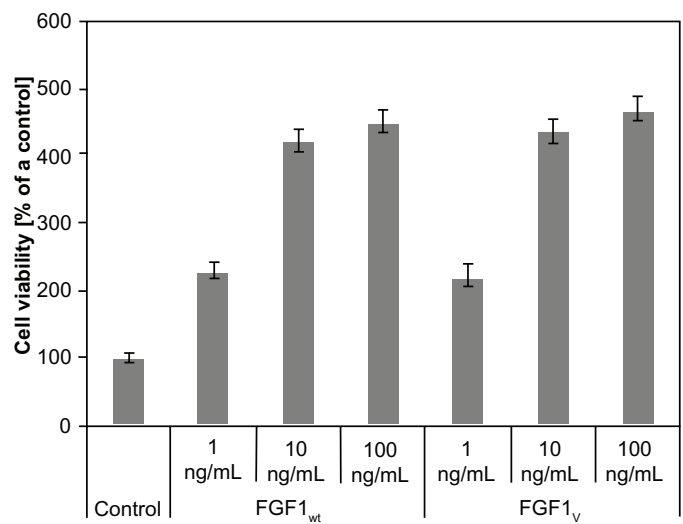

Figure I FGFI variant dedicated for specific conjugation with gold nanoparticles. (A) The spatial structure of FGFI with the introduced mutations (based on PDB: 2Q9X). Side chains of mutated residues involved in stability effects are represented in orange; mutations designed to facilitate thiol-mediated conjugation are marked in red. (B) Fluorescence (upper panel) and circular dichromism (lower panel) spectra of native wild-type FGFI, native $\mathrm{FGFI}_{\mathrm{v}}$, and denaturated $\mathrm{FGFI}_{\mathrm{v}}$ at a protein concentration of $2 \times 10^{-6} \mathrm{M}$ in $25 \mathrm{mM}$ sodium phosphate buffer, $\mathrm{pH}$ 7.3. (C) Normalized thermal denaturation curves of FGFI wild-type (in black) and engineered FGFI variant (in blue). Changes in ellipticity were monitored at $228 \mathrm{~nm}$ wavelength, in the presence of $0.7 \mathrm{M} \mathrm{GdmCl}$ in $25 \mathrm{mM}$ sodium phosphate buffer, pH 7.3, and at a protein concentration of $2 \times 10^{-6} \mathrm{M}$. (D) Proliferative activity of FGFI and wild-type FGFI measured by the MTT assay.

Notes: Starved NIH 3T3 cells were incubated with the growth factor for 48 hours in the presence of I0 U/mL heparin. Equal volume of PBS was added to the control samples. Results shown are mean values from four experiments. Bars indicate $+/-$ standard deviation.

Abbreviations: FGFI, fibroblast growth factor I; PDB, Protein Data Bank; FGFI ${ }_{\vee}$, fibroblast growth factor I variant; MTT, 3-(4,5-dimethylthiazol-2-yl)-2,5-diphenyltetrazolium bromide; NIH 3T3, mouse embryonic fibroblast cell line; PBS, phosphate buffered saline.

described triple variant (Gln40Pro, Ser47Ile, His93Gly). ${ }^{8}$ In conclusion, the addition of the cysteine-containing linker at the $\mathrm{N}$ terminus together with Cys117Ser substitution did not lead to any substantial changes in protein stability.

To verify whether the introduced modifications did not affect the growth factor's biological activities, especially receptor binding and activation, cell proliferation assay in the NIH 3T3 cells was performed (in the presence of heparin). $F G F 1_{v}$ engineered for nanoparticle coating showed the same proliferation potential as the wt FGF1, which in the presence of heparin is very similar to the triple FGF1 stable mutant (Gln40Pro, Ser47Ile, His93Gly) activity (Figure 1D).

\section{AuNP preparation and characterization}

AuNPs are widely used in nanobiotechnology and are considered to be representative nanomaterial. ${ }^{23}$ Several methods of their synthesis have been developed, which differ in the capping agent, product size, shape, and tendency 
to aggregation. ${ }^{24}$ Protein conjugation to AuNPs needs to be performed in a hydrophilic solution and under mild $\mathrm{pH}$ conditions. For this reason we synthesized nanoparticles using the Turkevich method. ${ }^{16,17}$ After synthesis, the AuNPs were stabilized with citrate ions, which were subsequently exchanged for detergent molecules, and finally for the protein thiol group (Figure 2A). Synthesized nanoparticles were characterized with UV-Vis absorption spectroscopy (Figure 2B). They displayed a characteristic band with the maximum absorption at $520 \mathrm{~nm}$, corresponding to the average size of nanoparticles of $10 \mathrm{~nm}$ in diameter. ${ }^{25}$ This result was also confirmed by electron microscopy and by DLS measurements (Figure 2C and D). The solution was monodisperse and did not contain any aggregates.

\section{Preparation of FGFI-AuNP conjugates}

Proteins can be conveniently attached to the surface of the AuNPs via a strong covalent bond between cysteine thiol and gold. Since gold colloids without a capping agent are prone to aggregation, ${ }^{23}$ we conducted two-step functionalization to minimize the risk of gold colloid's aggregation; the developed protocol was based on the detergent exchange approach. ${ }^{26,27}$ After the initial coating of the nanoparticles with a low concentration of a nonionic detergent, the detergent molecules were gradually exchanged for the protein molecules. The excess of protein was completely removed in several subsequent washing steps, as determined by MS.

To choose the optimal detergent for coating of AuNPs with $F G F 1_{\vee}$ yielding a monodisperse colloid preparation, we tested 14 detergents with different molecular structures and properties representing four groups: polyoxythylenes, alkyl glycosides, zwittergents, and glucamides. The results are summarized in Table 1 . In general, alkyl glucosides proved to be the most effective in the preparation of the protein-nanoparticle conjugates, with polyoxyethylenes being slightly less effective, whereas zwittergents and glucamides yielded colloids prone to aggregation. In this particular system, n-decyl- $\beta$-D-maltoside allowed us to produce monodisperse, stable, high-yielding gold colloids, and was used in all subsequent preparations.

\section{Characterization of FGFI ${ }_{\mathrm{v}}-\mathrm{AuNP}$ conjugates}

The UV-Vis spectrum measurement confirmed that $F G F 1_{V^{-}}$ AuNPs were monodisperse (Figure 2B) with a hydrodynamic diameter of $17.3 \mathrm{~nm}$ as established by DLS (Figure 2D). Noncoated AuNPs were approximately $9 \mathrm{~nm}$ in diameter, thus the increase in the hydrodiameter of $F G F 1_{V}-A u N P s$ suggested the presence of covalently bound $F G F 1_{V}$ on the surface of nanoparticles. FGF1 $1_{\mathrm{V}}$-AuNPs did not show any signs of aggregation when visualized by transmission electron microscopy (Figure 2C). Importantly, FGF1 $1_{\mathrm{V}}$-AuNPs retained colloidal properties even in high salt concentrations, which caused aggregation of noncoated colloids (Figure 2E).

The presence of $F G F 1_{V}$ on the surface of gold colloids was additionally confirmed by MS and Western blot analysis. To identify $F G F 1_{v}$ via MS, conjugates were reduced with high concentrations of reducing agents ( $0.5 \mathrm{M}$ DTT or $0.1 \mathrm{M}$ TCEP). The reduced sample yielded the mass spectrum of intact $F G F 1_{\vee}$, whereas the untreated conjugate did not result in any peaks in the range of the free FGF1 mass (Figure 3A and B). Both samples were also verified by Western blot analysis with the use of anti-FGF1 antibody confirmed by the MS analysis (Figure 3C, upper panel). For the verification of FGF1 presence on the nanoparticle surface, we have also employed a second MS approach, which involved trypsin digestion of conjugates and subsequent identification of tryptic peptides. This method revealed the presence of $F G F 1_{V}$ peptides in the $F G F 1_{V}$-AuNPs sample and confirmed the presence of $F G F 1_{V}$ on the surface of conjugates (Figure 3D).

The solution from the last washing step of the conjugate preparation was also subjected to Western blot and MS analyses. There was not any trace of either the FGF1 band in immunoblotting assay, or of $F G F 1_{V}$ detected by MS (Figure 3C, lower panel). In addition, the absence of free FGF $1_{V}$ was confirmed by the proliferation assay in NIH 3 T3 cells. The last wash did not activate the FGFRs, and the downstream signaling cascades and did not stimulate NIH 3T3 fibroblast proliferation, confirming again that there was no free $F G F 1_{V}$ in the sample of $F G F 1_{V}$-AuNPs. Due to the spectral properties of AuNPs, spectroscopic measurements of protein concentration were not possible. Therefore, the concentration of $F G F 1_{V}$ conjugated to the AuNPs was estimated using a modified Bradford assay (Bio-Rad Protein Assay, Bio-Rad Laboratories).

\section{Biological activity of $\mathrm{FGFI}_{\mathrm{v}}$-AuNPs}

The biological activity of FGF $1_{V}$ conjugated to the AuNPs was tested using the NIH $3 \mathrm{~T} 3$ cell line. To establish whether the immobilized FGF1 is natively folded and retains its ability to bind to FGF receptors on the cell surface, we employed a proliferation assay. Serum-starved NIH 3 T3 cells were treated with varying concentrations of FGF1 and corresponding concentrations of $\mathrm{FGF} 1_{\mathrm{v}}$-AuNPs (with the 


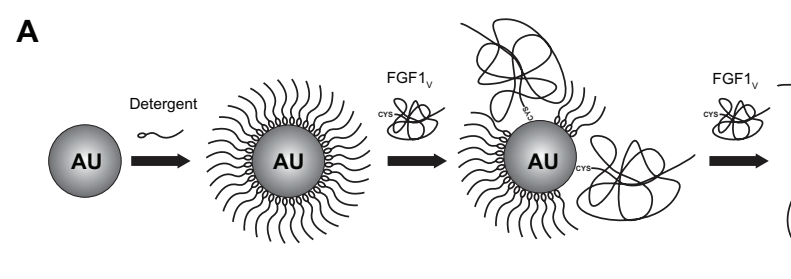

B
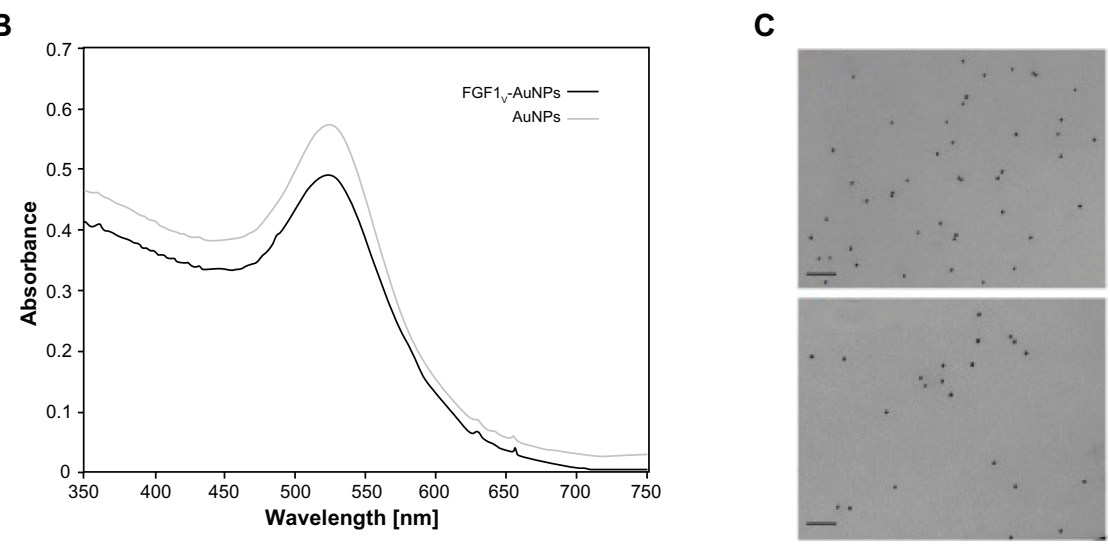

D

E
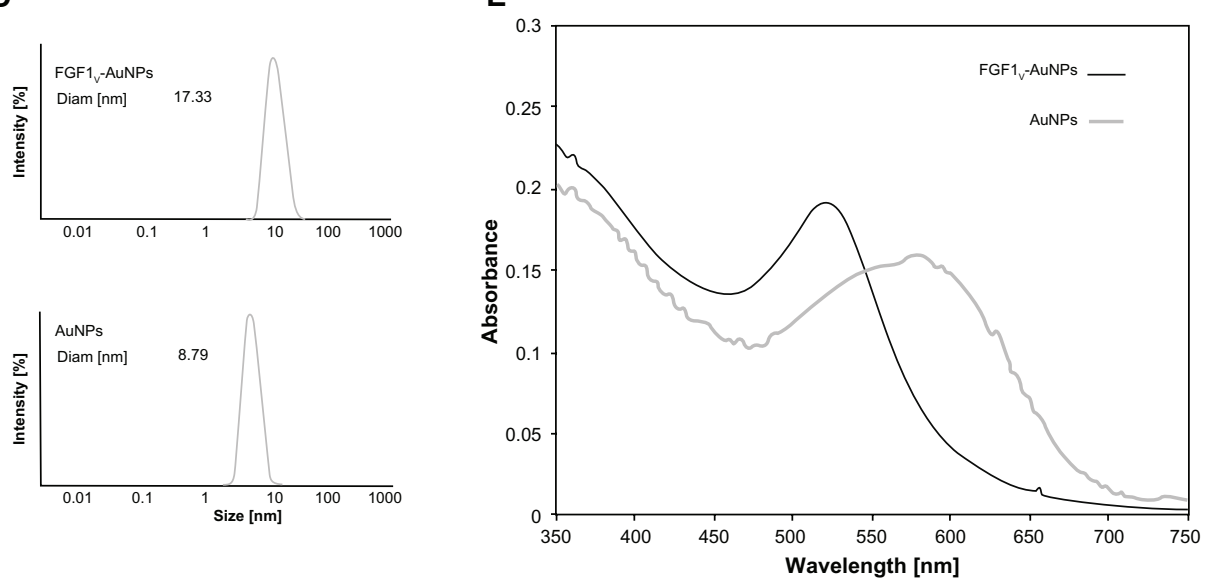

Figure 2 Biophysical characterization of AuNP conjugates. (A) Scheme of the two-step functionalization of AuNPs with FGFI based on the gradual exchange of detergent molecules for the protein. (B) UV-Vis spectrum of the synthesized gold colloids and FGFI $v_{v}$-coated gold colloids (FGFI - $^{-A u N P s}$ ). (C) Transmission electron microscopy image of gold colloid solution and AuNPs coated with FGFI . Bar equals to $100 \mu \mathrm{m}$. (D) DLS analysis of AuNPs coated with FGFI (upper panel) and synthesized unconjugated AuNPs (lower panel). (E) UV-Vis spectra of AuNPs treated with high salt concentration, coated with the $\mathrm{FGFI}_{\checkmark}\left(\mathrm{FGFI}_{\mathrm{v}}\right.$-AuNPs) and aggregated AuNPs without any coating agent.

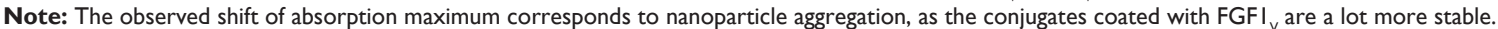

Abbreviations: AuNP, gold nanoparticle; Au, gold; FGFI ${ }_{v}$, fibroblast growth factor I variant; UV-Vis, ultraviolet visible spectroscopy; DLS, dynamic light scattering.

same amount of $F G F 1_{v}$ ) and gold colloids alone (with the same amount of AuNPs). As shown in Figure 4A, the colloid-bound FGF $1_{V}$ stimulates the proliferation of the $\mathrm{NIH}$ $3 \mathrm{~T} 3$ cells at a level comparable to $\mathrm{FGF} 1_{\mathrm{V}}$ In agreement with the proliferation assay, FGF1 $1_{\mathrm{v}}$-AuNPs activated all main FGF1-induced signaling pathways (Figure 4B). Furthermore, FGF1 $1_{\mathrm{v}}$-AuNPs showed a moderate proliferative effect, presumably due to the presence of a functional growth factor on their surface. These results show that the FGF $1_{V}$ covalent bond to gold colloids is properly folded, fully functional, and not cytotoxic for the cells.

\section{FGFR-mediated specific cell uptake of $\mathrm{FGFI}_{\mathrm{v}}$-AuNPs}

To determine if the $\mathrm{FGF} 1_{\mathrm{V}}$-AuNP particle conjugates can be efficiently internalized in an FGFR-dependent manner, we employed two model cell lines: U2OS and U2OS, stably transfected with FGFR1 (U2OS R1), as described previously by Haugsten et al. ${ }^{19}$ Untransfected U2OS cells did not express any FGFR isoforms, and thus could serve as a negative control, as confirmed by quantitative reverse transcription polymerase chain reaction. Fluorescently labeled $F G F 1_{v}$ (FITC-FGF $1_{\mathrm{v}}$ ) was attached to the surface of AuNPs via the 
Table I Detergents tested for the preparation of gold colloids coated with FGFI

\begin{tabular}{|c|c|c|c|c|c|}
\hline Reagent & Detergent & MW average & $\mathrm{CMC}[\mathrm{mM}]$ & Type & NP conjugation \\
\hline 1 & TRITON ${ }^{\circledR} X-100$ & 650.0 & 0.90 & Polyoxyethylenes & + \\
\hline 2 & $\mathrm{C}_{12} \mathrm{E}_{8}$ & 538.8 & 0.11 & Polyoxyethylenes & + \\
\hline 3 & $\mathrm{C}_{12} \mathrm{E}_{9}$ & 583 & 0.05 & Polyoxyethylenes & + \\
\hline 4 & Tween 20 & 1227.5 & 0.08 & Polyoxyethylenes & ++ \\
\hline 5 & n-Hexyl- $\beta$-D-glucopyranoside & 264.3 & 250.00 & Alkyl glycosides & + \\
\hline 6 & n-Octyl- $\beta$-D-glucoside & 292.4 & 20.00 & Alkyl glycosides & ++ \\
\hline 7 & n-Decyl- $\beta$-D-maltoside & 482.6 & 1.80 & Alkyl glycosides & ++ \\
\hline 8 & n-Dodecyl- $\beta$-D-maltoside & 510.6 & 0.17 & Alkyl glycosides & ++ \\
\hline 9 & ZWITTERGENT ${ }^{\circledR} 3-10$ & 307.6 & 40.00 & Zwittergent & $+1-$ \\
\hline 10 & ZWITTERGENT ${ }^{\circledR} 3-12$ & 335.6 & 4.00 & Zwittergent & $+1-$ \\
\hline 11 & LDAO & 229.41 & 2.00 & Zwittergent & - \\
\hline 12 & DDAO & 201.35 & 10.40 & Zwittergent & - \\
\hline 13 & Big CHAP, Deoxy & 862.1 & 1.40 & Glucamides & - \\
\hline 14 & $\mathrm{MEGA}^{\Theta_{-}-8}$ & 321.4 & 79.00 & Glucamides & - \\
\hline
\end{tabular}

Notes: Nanoparticle conjugation efficiency was judged based on coated nanoparticle monodispersity, resistance to salt-induced aggregation, and effective replacement with protein. $(+++)$ denotes the detergent yielding nanoparticles with best characteristics, while $(++),(+)$, and $(+l-)$ correspond to detergents that were relatively less efficient, yielding less dispersed colloids. $(-)$ indicates that the detergent does not prevent colloid aggregation during coating.

Abbreviations: $\mathrm{FGFI}_{\mathrm{v}}$, fibroblast growth factor I variant; MW, molecular weight; CMC, critical micelle concentration; NP, nanoparticles; LDAO, lauryldimethylamine $\mathrm{N}$-oxide; DDAO, N,N-dimethyldodecylamine $\mathrm{N}$-oxide.

protocol described earlier. The conjugates (FITC-FGF1 ${ }_{\mathrm{V}^{-}}$ AuNPs) or free FITC-FGF1 ${ }_{v}$ were incubated with U2OS and U2OS R1 cells for 30 minutes at $37^{\circ} \mathrm{C}$, and they were then analyzed with a confocal laser scanning microscope. In order to directly visualize AuNPs, we have employed the resonance light scattering of AuNPs. ${ }^{28}$ We observed that both fluorescently labeled free $F G F 1_{\mathrm{v}}$ and $\mathrm{FGF} 1_{\mathrm{v}}$-AuNPs were internalized by FGFR1-expressing cells (U2OS R1), which was in clear contrast to the FGFR-deficient cells (U2OS). The presence of AuNPs (by reflectance mode) was detected only in the U2OS R1 cells, and they colocalized with FGF1 ${ }_{\mathrm{v}}$-FITC (Figure 5). These results confirm that $\mathrm{FGF} 1_{\mathrm{v}}$-nanoparticle conjugates were internalized in a receptor-dependent manner.

\section{NIR induced hyperthermia in FGFR- positive cells treated with $\mathrm{FGFI}_{\mathrm{v}}-\mathrm{AuNPs}$}

Finally, we evaluated the applicability of the FGF $1_{\mathrm{v}^{-}}$ coated nanoparticles for the targeted photothermal therapy. Untransfected U2OS cells, U2OS R1 cells highly expressing FGFR1, and BJ cells naturally expressing FGFR1 were treated with $F G F 1_{\mathrm{v}}$-AuNPs or AuNPs and then irradiated with NIR light ( $808 \mathrm{~nm}$ ). The level of FGFR1 expression in the $\mathrm{BJ}$ cells was quite high as compared to the other primary cells. Both FGFR-positive cell lines showed significantly decreased viability upon NIR irradiation (39\% of the initial viability in the case of U2OS R 1 cells, and $58 \%$ of the initial viability in the case of BJ cells), whereas in cell line lacking FGFR (U2OS cells) no effect of irradiation in the presence of $\mathrm{FGF} 1_{\mathrm{V}}$-AuNPs was observed (viability equal to $95 \%$ of untreated controls) (Figure 6A and B). Both cell lines were also exposed to $808 \mathrm{~nm}$ laser irradiation in the absence of FGF $1_{\mathrm{v}}$-AuNPs, and incubated with $\mathrm{FGF} 1_{\mathrm{v}}$-AuNPs without laser light treatment. Cells treated with uncoated AuNPs served as an additional negative control (treated and untreated with infrared light).

Laser irradiation of cells untreated with conjugates did not yield significant cytotoxicity; this was similar to cells treated with nanoparticles in the absence of laser irradiation (Figure 6A and B). This indicates that neither nanoparticles nor laser light itself could be toxic for cells and influence their viability. On the contrary, $\mathrm{FGF} 1_{\mathrm{v}}$-AuNPs alone showed a slight increase in viability, presumably caused by the proliferation activity of the $\mathrm{FGF} 1_{\mathrm{v}}$ of conjugates.

Taken together, the photothermally induced cell damage was prominent only for cell lines expressing FGFR1, which is in agreement with the receptor-specific internalization of nanoconjugates shown above (Figure 5).

\section{Discussion}

FGFRs meet the expectations for potential therapeutic targets, as significant amplification of FGFRs has been identified in various tumor types. ${ }^{6}$ Currently there are several different strategies to develop an effective anticancer therapy of the FGFR-related tumors. They include the application of small-molecule tyrosine kinase inhibitors, ${ }^{29,30}$ FGF ligand traps preventing FGFs from binding to their receptors, ${ }^{31}$ and monoclonal antibodies against FGFs and FGFRs. ${ }^{32,33}$ 

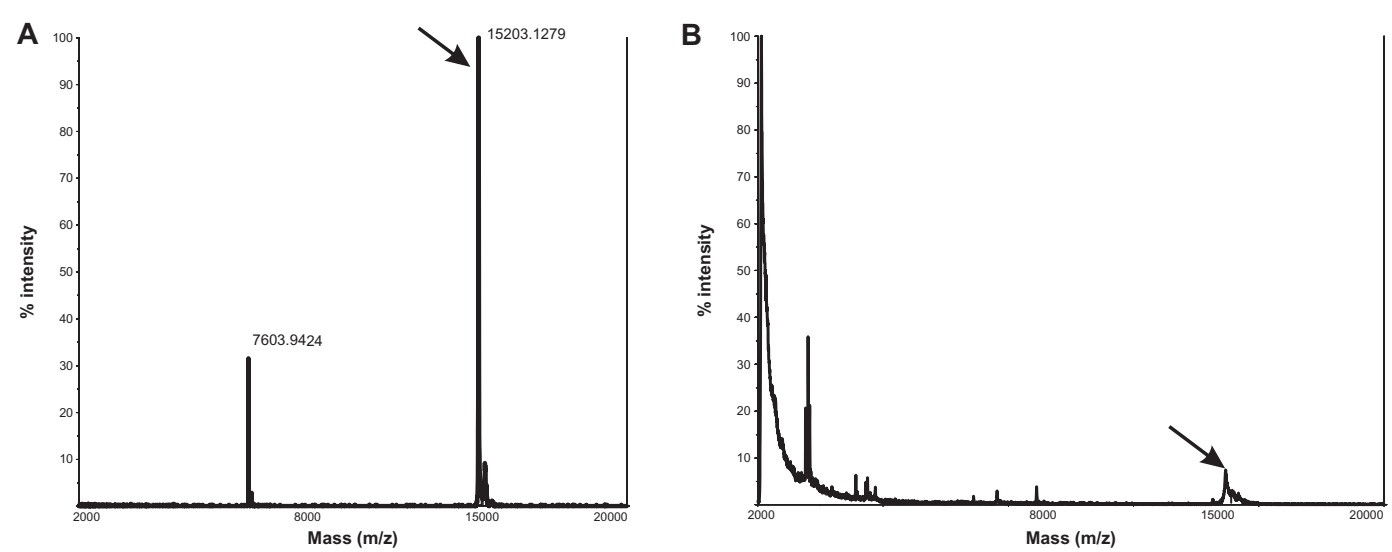

C

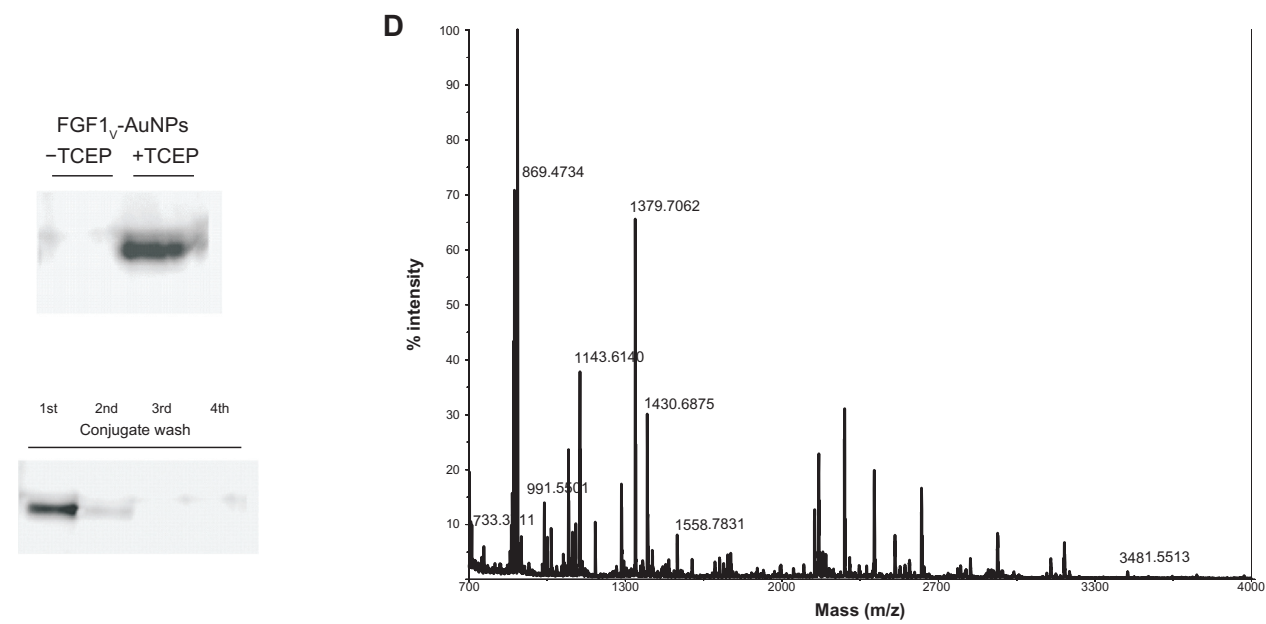

Figure 3 Biophysical characterization of $\mathrm{FGFI}_{\mathrm{V}}$-gold nanoparticles. (A) Mass spectrometry analysis of intact $\mathrm{FGFI}_{\mathrm{V}}$. (B) Mass analysis of $\mathrm{FGFI}_{\mathrm{V}}$-gold nanoparticles reduced with TCEP. (C) Western blot analysis of conjugates and their preparation steps with anti-FGFI antibody. Upon SDS-PAGE, separation FGFI can be detected only after reduction by TCEP - when released from the nanoparticle surface. (D) Mass spectrometry analysis of trypsin digest of FGFI $\mathrm{v}_{\mathrm{v}}$-coated gold nanoparticles.

Note: Tryptic peptides corresponding to the FGFI sequence are annotated.

Abbreviations: $\mathrm{FGFI}_{v}$, fibroblast growth factor I variant; TCEP, tris(2-carboxyethyl)phosphone; FGFI, fibroblast growth factor I; SDS-PAGE, sodium dodecyl sulfate polyacrylamide gel electrophoresis.

A

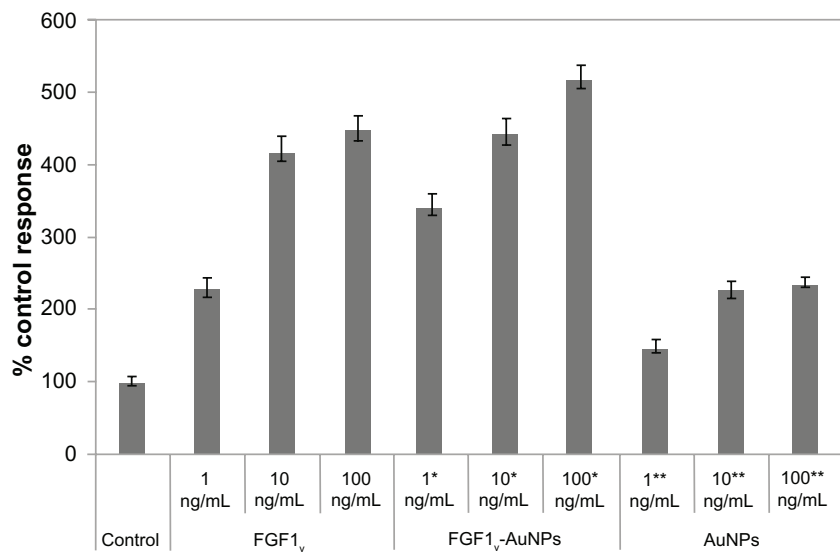

B

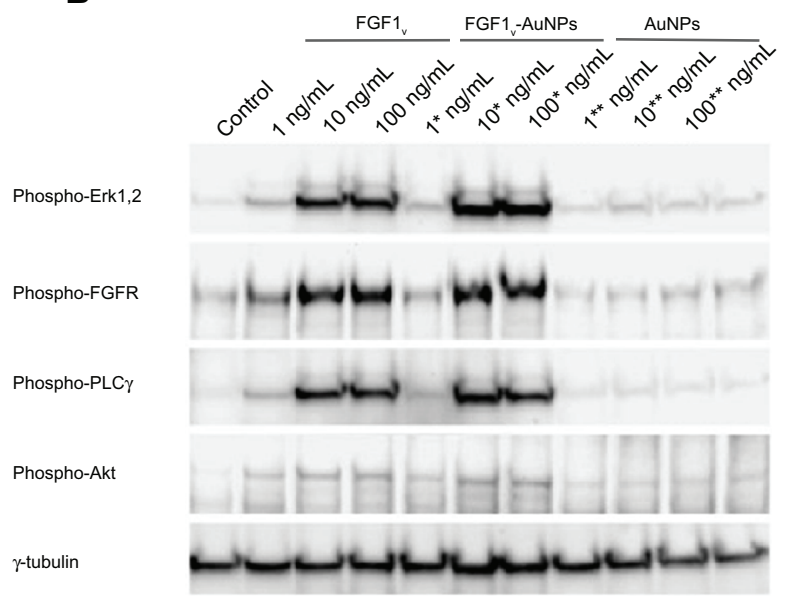

Figure 4 Biological activity of $\mathrm{FGFI}_{\mathrm{v}}$-AuNP conjugates. (A) Cell proliferation in response to $\mathrm{FGFI}_{\mathrm{v}}, \mathrm{FGFI}_{\mathrm{v}}$-AuNPs, and nanoparticle colloids alone (AuNPs) measured using Alamar Blue assay. Starved NIH 3T3 cells were incubated with the growth factor for 48 hours in the presence of $10 \mathrm{U} / \mathrm{mL}$ heparin. Equal volume of PBS was added to the control samples. Results shown are mean values from four experiments. Bars indicate $+/-$ standard deviation. (B) Activation of signaling cascades in NIH 3 T3 cells after

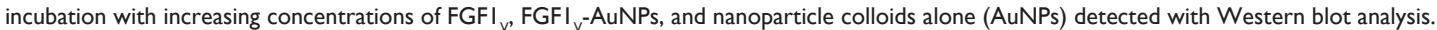

Notes: I*, 10*, and 100* $\mathrm{ng} / \mathrm{mL}$ AuNPs denotes the concentration of AuNPs equal to the concentration of AuNPs in I*, I0*, and I00* ng/mL FGFI - -AuNPs. Abbreviations: $\mathrm{FGFI}_{v}$, fibroblast growth factor I variant; AuNP, gold nanoparticle; PLC $\gamma$, phospholipase C-gamma; NIH 3T3, mouse embryonic fibroblast cell line; PBS, phosphate buffered saline. 

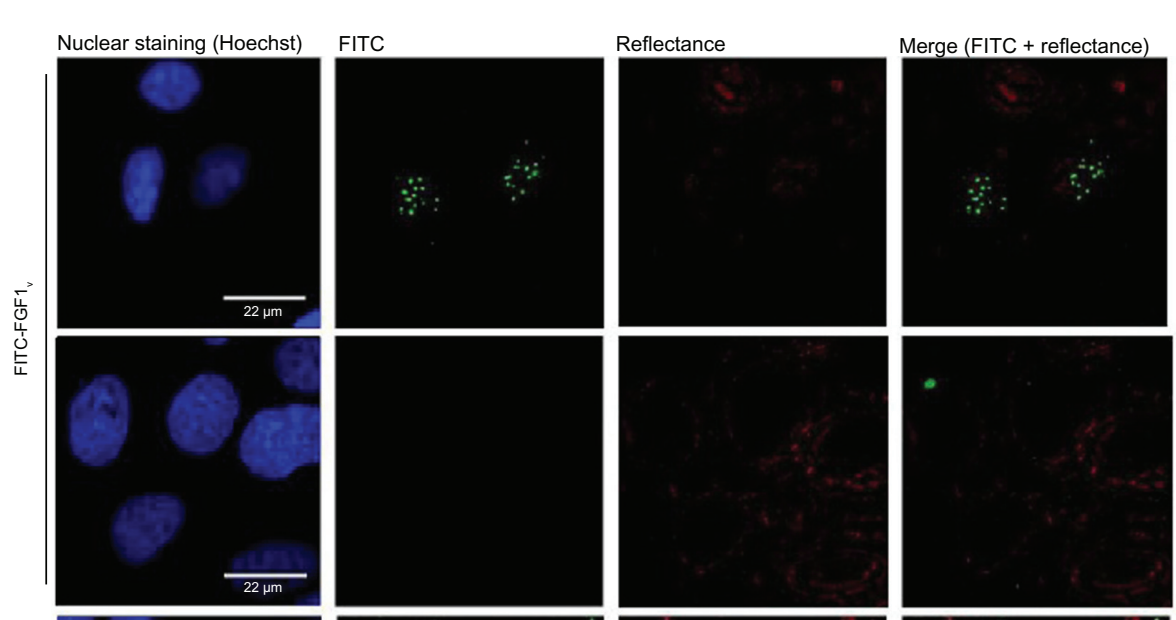

Merge (FITC + reflectance +

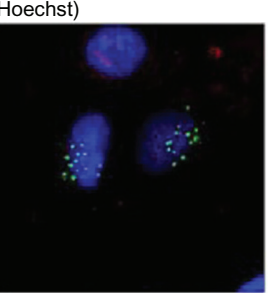

Cell line

U20S R1
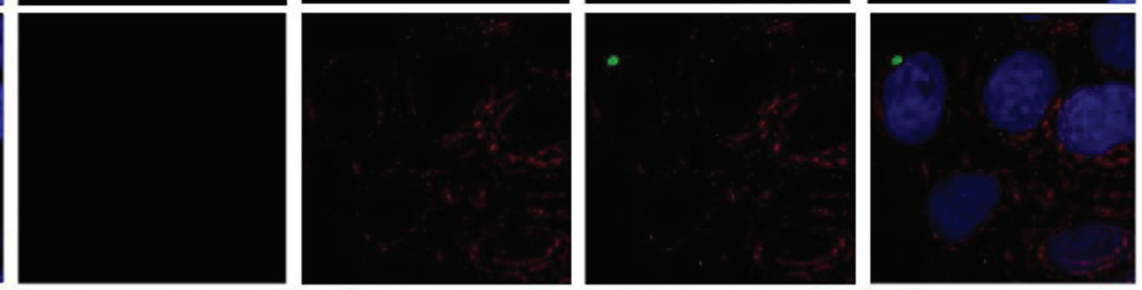

U20S
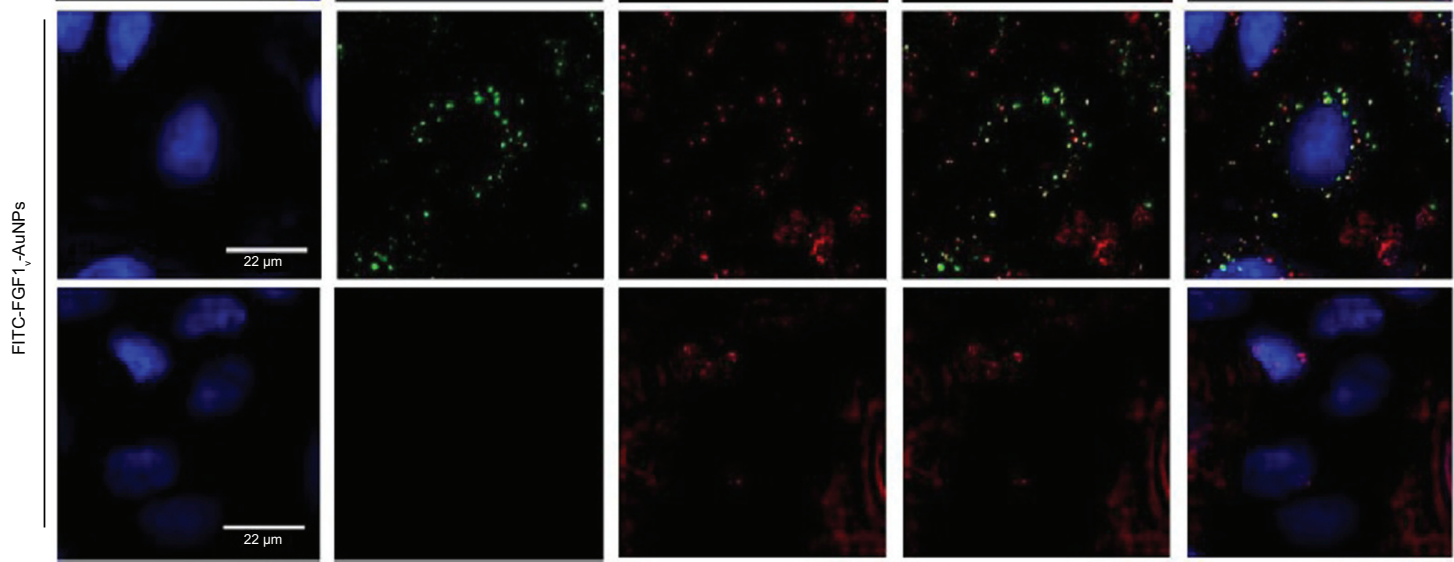

U20S R1
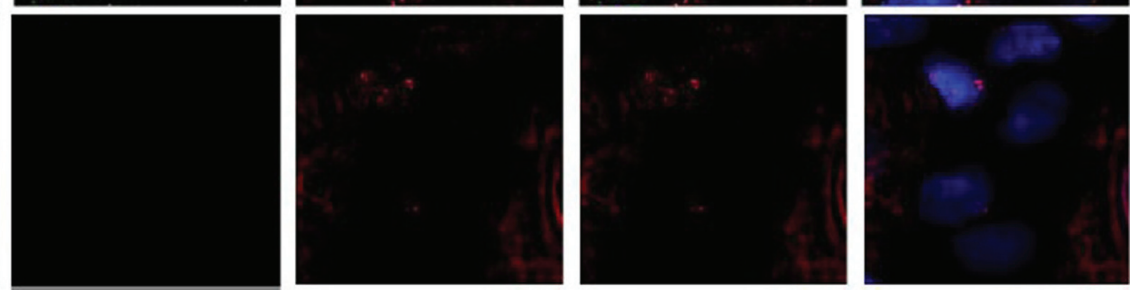

Figure 5 Receptor-specific internalization of $\mathrm{FGFI}_{v}$ or $\mathrm{FGFI}_{\checkmark}$-AuNPs visualized with confocal fluorescence microscopy.

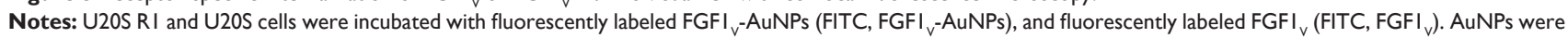
detected with confocal reflectance and cell nuclei were visualized with Hoechst staining. Only cells expressing FGF receptor internalized conjugates.

Abbreviations: $\mathrm{FGFI}_{\mathrm{V}}$, fibroblast growth factor I variant; AuNPs, gold nanoparticles; FITC, fluorescein isothiocyanate.

In this report, we evaluate a novel approach of targeting tumors overexpressing FGFRs with their natural ligand, FGF1, conjugated with AuNPs.

To exploit FGF1 targeting potential, we designed a new variant of this growth factor suitable for therapeutic application. Based on the formerly characterized stable FGF1 mutant, ${ }^{8}$ we engineered a protein $\left(\mathrm{FGF}_{\mathrm{v}}\right)$ containing three stabilizing point mutations that overcame low stability and the relatively short half-life in vivo of the wt FGF1, Cys117Ser substitution to eliminate Cys on the protein surface, and N-terminal CysGly-Gly-Gly flexible linker to enable precise site-directed conjugation of FGF1 to gold. The engineered $\mathrm{FGF}_{\mathrm{V}}$ was properly folded, highly stable, and showed biological activity well comparable to the wt FGF1. These properties were preserved upon conjugation to AuNPs.

FGF conjugates previously studied in the form of fusion proteins with bacterial toxins (such as diphtheria toxin and Pseudomonas exotoxin) were shown to kill tumor cells. . $^{34,35}$ The main obstacle was the high immunogenicity effect evoked by these fusions in vivo. Alternatively, the $\mathrm{FGF} 1_{\mathrm{v}^{-}}$ AuNP conjugates that we synthesized are expected to exhibit minimal immunogenicity due to the good biocompatibility of AuNPs in vivo. ${ }^{36}$

Gold colloids comprise a novel group of potential anticancer agents. Given their plasmonic absorption in the NIR range, which can be effectively converted into thermal energy, they can be used to evoke localized heating within the tissues leading to tumor cell death (called thermoablation or hyperthermia).${ }^{37}$ Due to the low permeability of NIR into the tissues, photothermal therapies involving plasmonic AuNPs were limited to the penetration range of available lasers. However, in the 650-900 $\mathrm{nm}$ region where the absorption of physiological fluids and tissues is minimal, the Food and Drug Administration Class 1 (microwatt) laser can efficiently penetrate up to $10 \mathrm{~cm}$ through the tissue..$^{38}$ The efficiency of AuNP-based systems can be further improved by their conjugation with targeting molecules, and these were shown to be suitable for therapy against solid tumors. ${ }^{39}$ 

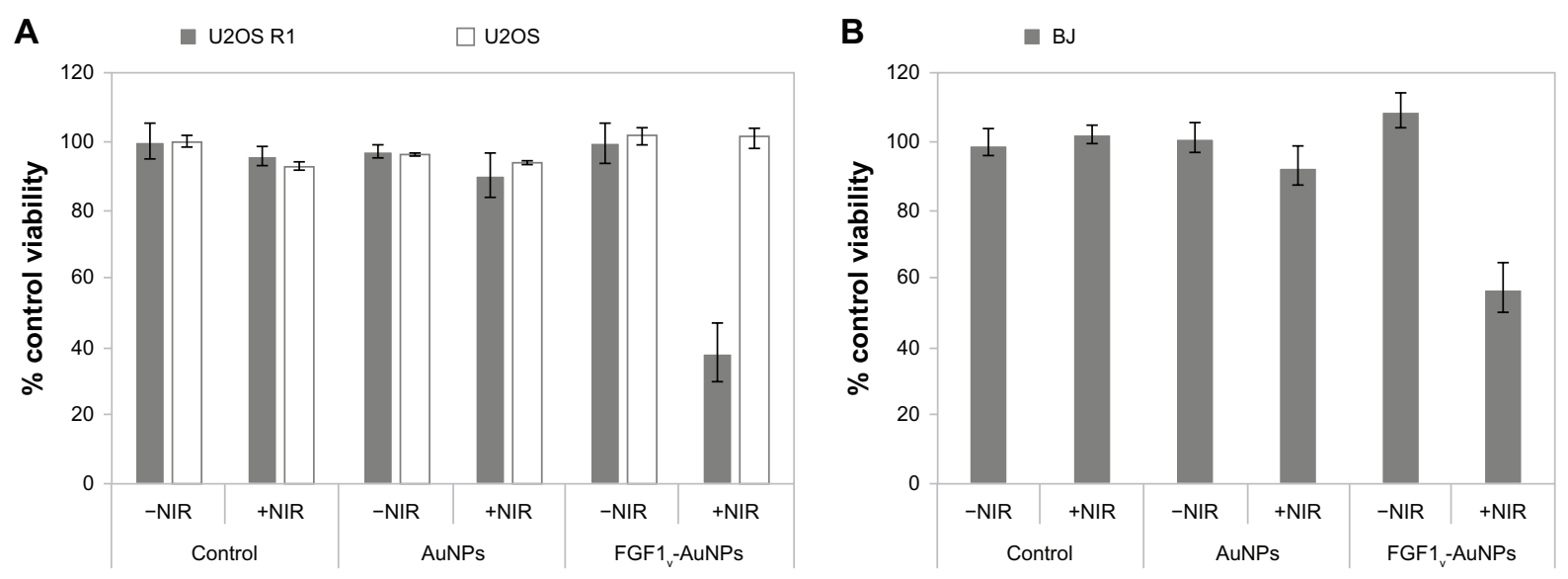

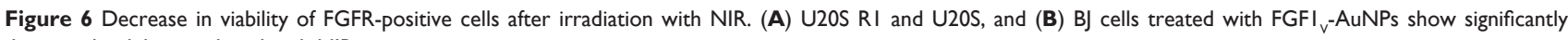
decreased viability irradiated with NIR.

Notes: Results shown are mean values from three experiments. Bars indicate +/- standard deviation. Cells were treated with NIR (808 nm diode laser, I.2 A) for 20 minutes, and the visibility was measured by the MTT assay 12 hours after NIR treatment. Equal volume of PBS was added to the control samples.

Abbreviations: FGFR, fibroblast growth factor receptor; NIR, near-infrared; FGFI , fibroblast growth factor I variant; AuNPs, gold nanoparticles; MTT, 3-(4,5dimethylthiazol-2-yl)-2,5-diphenyltetrazolium bromide; PBS, phosphate buffered saline.

Kogot et $\mathrm{al}^{40}$ demonstrated that the FGF1 wt can be effectively conjugated via His-tag to the CAAKA peptide passivated AuNPs of $1.5 \mathrm{~nm}$; however, they did not present how coupling with the nanoparticle affected the biological activity of the growth factor. The system used in this study, which was based on much larger, $10 \mathrm{~nm}$ nanoparticles, presents different advantages together with different challenges to be overcome. The major benefit is that larger nanoparticles are much more effective for the photothermal therapy of cancerous cells.

The $10 \mathrm{~nm}$ AuNPs suitable for photothermal therapy are much larger than the FGF $1_{\mathrm{v}}$ molecule itself, and the major difficulties to overcome during the conjugation process were the direct and unspecific hydrophobic interactions of protein and nanoparticle surfaces, leading to protein denaturation and loss of function. Using the detergent exchange approach with a panel of different detergent types, we developed and further optimized a protocol yielding nanoparticles coated with FGF $1_{v}$ covalently bound to a gold surface that were monodisperse and retained protein functionality. The covalent attachment of FGF $1_{v}$ to AuNPs was verified by several methods including a reduction protocol followed by MS analysis. After incubation in a highly reductive environment, conjugated proteins could be released from the nanoparticles and identified by MS. This approach provides a robust, reliable, and versatile method to determine the proper conjugation of protein to AuNPs, and should be universal and suitable for other gold-thiol based systems.

Precise targeting of cancer cells is the most crucial aspect of successful antitumor therapies. Specific ligands should not only mark the cancerous cell, but also be specifically internalized in order to act intracellularly and not affect the surrounding healthy cells. ${ }^{41}$ In cell culture experiments, we showed that $F G F 1_{V}$ conjugated to AuNPs remained properly folded and biologically active, and that the $\mathrm{FGF} 1_{\mathrm{V}}$-AuNPs were only internalized specifically by cells expressing FGFRs. Thus, our report demonstrates that $F G F 1_{v}$ is a promising delivery agent for cancer cells expressing FGFRs. Moreover, apart from being targeted by FGF1 to the cell surface of FGFR-overexpressing cells, the nanoparticles could also preferentially accumulate at the tumor site due to the enhanced permeability and retention effect, achieving even higher intratumoral concentrations useful for subsequent treatment with NIR. ${ }^{42,43}$

Finally, we showed that irradiation with NIR laser light allows for effective and specific photothermal destruction of cancer cells expressing FGF receptors on their surface upon treatment with FGF $1_{\mathrm{v}}$-AuNPs. After single 20-minute irradiation with $808 \mathrm{~nm}$ light, the viability of FGFR1-expressing cells decreased by about $60 \%$. This result clearly shows the potential applicability of novel growth-factor targeted AuNPs in cancer treatment. Even though the laser wavelength used for irradiation was significantly different from the surface plasmon resonance wavelength of AuNPs, the cytotoxic effect was observed, and we believe that it was due to the second harmonic generation described previously. ${ }^{44,45}$ Indeed, previous studies have shown the applicability of NIR irradiation with AuNPs, and that the required laser power of NIR irradiation $(800 \mathrm{~nm})$ was ten times lower than for the visible $(520 \mathrm{~nm})$ light treatment. ${ }^{11}$ Furthermore, it was 
previously suggested that due to the close proximity of the nanoparticles in the endosomes, their absorption spectrum may shift to the NIR region. ${ }^{46}$ Additionally, NIR irradiation offers the advantage of being highly permeable in tissues when compared to visible light. ${ }^{47}$

Our study is the first report employing engineered FGFtype ligands to the specific delivery of AuNPs to cancer cells via FGFR1-mediated endocytosis. The results presented show the potential applicability of FGF1-gold conjugates in further animal studies using FGFR-expressing xenografts, which may lead to the development of a novel anticancer therapy in the future.

\section{Acknowledgments}

This work was supported by the Wroclaw Research Center EIT+ under the project Biotechnologies and advanced medical technologies - BioMed (POIG 01.01.02-02-003/08-00) financed from the European Regional Development Fund (Operational Program Innovative Economy, 1.1.2).

We thank Dr Michał Majkowski from the Laboratory of Cytobiochemistry, University of Wroclaw; Dr Jorgen Wesche from the Department of Biochemistry, Institute for Cancer Research; the Norwegian Radium Hospital for help with confocal microscopy experiments; and the skillful technical assistance of Anne Engen and Anne-Mari G Pedersen from the Department of Biochemistry, Institute for Cancer Research. The Norwegian Radium Hospital is gratefully acknowledged.

\section{Disclosure}

The authors report no conflicts of interest in this work.

\section{References}

1. Blanco E, Hsiao A, Ruiz-Esparza GU, Landry MG, Meric-Bernstam F, Ferrari M. Molecular-targeted nanotherapies in cancer: enabling treatment specificity. Mol Oncol. 2011;5(6):492-503.

2. Knights V, Cook SJ. De-regulated FGF receptors as therapeutic targets in cancer. Pharmacol Ther. 2010;125(1):105-117.

3. Haugsten EM, Wiedlocha A, Olsnes S. Roles of Fibroblast Growth Factor Receptors in Carcinogenesis. Mol Canc Res. 2010; 8:1439-1452.

4. Penault-Llorca F, Bertucci F, Adélaide J, et al. Expression of FGF and FGF receptor genes in human breast cancer. Int J Cancer. 1995; 61(2):170-176.

5. Heinzle C, Sutterlüty H, Grusch M, Grasl-Kraupp B, Berger W, Marian B. Targeting fibroblast-growth-factor-receptor-dependent signaling for cancer therapy. Expert Opin Ther Targets. 2011;15(7): 829-846.

6. Wesche J, Haglund K, Haugsten EM. Fibroblast growth factors and their receptors in cancer. Biochem J. 2011;437(2):199-213.

7. Ornitz DM, Itoh N. Fibroblast growth factors. Genome Biol. 2001; 2(3):REVIEWS3005.

8. Zakrzewska M, Krowarsch D, Wiedlocha A, Olsnes S, Otlewski J. Highly stable mutants of human fibroblast growth factor-1 exhibit prolonged biological action. J Mol Biol. 2005;352(4):860-875.
9. El-Sayed IH, Huang X, El-Sayed MA. Selective laser photo-thermal therapy of epithelial carcinoma using anti-EGFR antibody conjugated gold nanoparticles. Cancer Lett. 2006;239(1):129-135.

10. Huang X, Jain PK, El-Sayed IH, El-Sayed MA. Determination of the minimum temperature required for selective photothermal destruction of cancer cells with the use of immunotargeted gold nanoparticles. Photochem Photobiol. 2006;82(2):412-417.

11. Huang X, Jain PK, El-Sayed IH, El-Sayed MA. Plasmonic photothermal therapy (PPTT) using gold nanoparticles. Lasers Med Sci. 2008;23(3):217-228.

12. Dykman L, Khlebtsov N. Gold nanoparticles in biomedical applications: recent advances and perspectives. Chem Soc Rev. 2012;41(6): 2256-2282.

13. Loo C, Lowery A, Halas N, West J, Drezek R. Immunotargeted nanoshells for integrated cancer imaging and therapy. Nano Lett. 2005;5(4):709-711.

14. Brust M, Walker M, Bethell D, Schiffrin DJ, Whyman R. Synthesis of thiol-derivatised gold nanoparticles in a two-phase liquid-liquid system. Journal of the Chemical Society, Chemical Communications. 1994;(7):801-802.

15. Perrault SD, Chan WC. Synthesis and surface modification of highly monodispersed, spherical gold nanoparticles of 50-200 nm. JAm Chem Soc. 2009;131(47):17042-17043.

16. Kimling J, Maier M, Okenve B, Kotaidis V, Ballot H, Plech A. Turkevich method for gold nanoparticle synthesis revisited. J Phys Chem B. 2006;110(32):15700-15707.

17. Turkevich J, Stevenson PC, Hillier J. A study of the nucleation and growth processes in the synthesis of colloidal gold. Discuss Faraday Soc. 1951;11:55-75.

18. Haugsten EM, Malecki J, Bjørklund SM, Olsnes S, Wesche J. Ubiquitination of fibroblast growth factor receptor 1 is required for its intracellular sorting but not for its endocytosis. Mol Biol Cell. 2008;19(8):3390-3403.

19. Haugsten EM, Sørensen V, Brech A, Olsnes S, Wesche J. Different intracellular trafficking of FGF1 endocytosed by the four homologous FGF receptors. J Cell Sci. 2005;118(Pt 17):3869-3881.

20. Ortega S, Schaeffer MT, Soderman D, et al. Conversion of cysteine to serine residues alters the activity, stability, and heparin dependence of acidic fibroblast growth factor. J Biol Chem. 1991;266(9):5842-5846.

21. Zakrzewska M, Krowarsch D, Wiedlocha A, Otlewski J. Design of fully active FGF-1 variants with increased stability. Protein Eng Des Sel. 2004;17(8):603-611.

22. Santoro MM, Bolen DW. A test of the linear extrapolation of unfolding free energy changes over an extended denaturant concentration range. Biochemistry. 1992;31(20):4901-4907.

23. Wilson R. The use of gold nanoparticles in diagnostics and detection. Chem Soc Rev. 2008;37(9):2028-2045.

24. Grzelczak M, Pérez-Juste J, Mulvaney P, Liz-Marzán LM. Shape control in gold nanoparticle synthesis. Chem Soc Rev. 2008;37(9): 1783-1791.

25. Jain PK, Lee KS, El-Sayed IH, El-Sayed MA. Calculated absorption and scattering properties of gold nanoparticles of different size, shape, and composition: applications in biological imaging and biomedicine. J Phys Chem B. 2006;110(14):7238-7248.

26. Aslan K, Lakowicz JR, Geddes CD. Nanogold-plasmon-resonancebased glucose sensing. Anal Biochem. 2004;330(1):145-155.

27. Aslan K, Pérez-Luna VH. Quenched emission of fluorescence by ligand functionalized gold nanoparticles. J Fluoresc. 2004;14(4):401-405.

28. Kah JC, Olivo MC, Lee CG, Sheppard CJ. Molecular contrast of EGFR expression using gold nanoparticles as a reflectance-based imaging probe. Mol Cell Probes. 2008;22(1):14-23.

29. Byron SA, Pollock PM. FGFR2 as a molecular target in endometrial cancer. Future Oncol. 2009;5(1):27-32.

30. Grand EK, Chase AJ, Heath C, Rahemtulla A, Cross NC. Targeting FGFR3 in multiple myeloma: inhibition of $\mathrm{t}(4 ; 14)$-positive cells by SU5402 and PD173074. Leukemia. 2004;18(5):962-966. 
31. Zhang H, Masuoka L, Baker K, et al. FP-1039 (FGFR1:Fc), A soluble FGFR1 receptor antagonist, inhibits tumor growth and angiogenesis. Proceedings of the AACR-NCI-EORTC International Conference Molecular Targets and Cancer Therapeutics Discovery, Biology and Clinical Applications; October 22-26, 2007; San Francisco, CA. Available at http://www.aacr.org/Uploads/DocumentRepository/2007conf/ moltar/mt07_posterb.pdf.

32. Desnoyers LR, Pai R, Ferrando RE, et al. Targeting FGF19 inhibits tumor growth in colon cancer xenograft and FGF19 transgenic hepatocellular carcinoma models. Oncogene. 2008;27(1):85-97.

33. Maruyama-Takahashi K, Shimada N, Imada T, et al. A neutralizing anti-fibroblast growth factor (FGF) 8 monoclonal antibody shows anti-tumor activity against FGF8b-expressing LNCaP xenografts in androgen-dependent and -independent conditions. Prostate. 2008; 68(6):640-650.

34. Gawlak SL, Pastan I, Siegall CB. Basic fibroblast growth factorPseudomonas exotoxin chimeric proteins; comparison with acidic fibroblast growth factor-Pseudomonas exotoxin. Bioconjug Chem. 1993;4(6):483-489.

35. Siegall CB, Gawlak SL, Chace DF, Merwin JR, Pastan I. In vivo activities of acidic fibroblast growth factor-Pseudomonas exotoxin fusion proteins. Bioconjug Chem. 1994;5(1):77-83.

36. Dreaden EC, Alkilany AM, Huang X, Murphy CJ, El-Sayed MA. The golden age: gold nanoparticles for biomedicine. Chem Soc Rev. 2012;41(7):2740-2779.

37. Cherukuri P, Glazer ES, Curley SA. Targeted hyperthermia using metal nanoparticles. Adv Drug Deliv Rev. 2010;62(3):339-345.
38. Dreaden EC, Mackey MA, Huang X, Kang B, El-Sayed MA. Beating cancer in multiple ways using nanogold. Chem Soc Rev. 2011;40(7):3391-3404.

39. Kennedy LC, Bear AS, Young JK, et al. T cells enhance gold nanoparticle delivery to tumors in vivo. Nanoscale Res Lett. 2011;6(1): 283.

40. Kogot JM, Parker AM, Lee J, Blaber M, Strouse GF, Logan TM. Analysis of the dynamics of assembly and structural impact for a histidine tagged FGF1-1.5 nm Au nanoparticle bioconjugate. Bioconjug Chem. 2009;20(11):2106-2113.

41. Sawyers C. Targeted cancer therapy. Nature. 2004;432(7015): 294-297.

42. Greish K. Enhanced permeability and retention of macromolecular drugs in solid tumors: a royal gate for targeted anticancer nanomedicines J Drug Target. 2007;15(7-8):457-464.

43. Hirsjärvi S, Passirani C, Benoit JP. Passive and active tumour targeting with nanocarriers. Curr Drug Discov Technol. 2011;8(3):188-196.

44. Lippitz M, van Dijk MA, Orrit M. Third-harmonic generation from single gold nanoparticles. Nano Lett. 2005;5(4):799-802.

45. Nappa J, Russier-Antoine I, Benichou E, Jonin Ch, Brevet PF. Second harmonic generation from small gold metallic particles: from the dipolar to the quadrupolar response. J Chem Phys. 2006;125(18):184712.

46. Zharov VP, Galitovskaya EN, Johnson C, Kelly T. Synergistic enhancement of selective nanophotothermolysis with gold nanoclusters: potential for cancer therapy. Lasers Surg Med. 2005;37(3):219-226.

47. Cheong WF, Prahl SA, Welch AJ. A review of the optical properties of biological tissues. IEEE Journal of Quantum Electronics. 1990;26(12): 2166-2185.
International Journal of Nanomedicine

\section{Publish your work in this journal}

The International Journal of Nanomedicine is an international, peerreviewed journal focusing on the application of nanotechnology in diagnostics, therapeutics, and drug delivery systems throughout the biomedical field. This journal is indexed on PubMed Central, MedLine, CAS, SciSearch $®$, Current Contents $₫ /$ Clinical Medicine,

\section{Dovepress}

Journal Citation Reports/Science Edition, EMBase, Scopus and the Elsevier Bibliographic databases. The manuscript management system is completely online and includes a very quick and fair peer-review system, which is all easy to use. Visit http://www.dovepress.com/ testimonials.php to read real quotes from published authors. 